\title{
Senster 2.0: Cultural context of media art curatorship
}

\author{
Anna Olszewska \\ AGH University of Science and Technology \\ Senster 2.0 Curator \\ Krakow, Poland \\ aolsz@agh.edu.pl
}

\begin{abstract}
In the following paper, I would like to explore what kind of knowledge and skills underpin an array of practices emerging during realisation of a media art museum project. Referring to a specific case study I argue that media art projects have potential to reframe contemporary practices via new research, design and execution modes of participation and operation.
\end{abstract}

Museums and collections. Media art. Literacies. Cultural analysis. Emerging cultural practices.

\section{INTRODUCTION}

The following paper summarises the process of restoration of the media art classic work called the Senster. I will present the project focusing on the kind of knowledge and skills required from professionals involved in its different stages. I will share observations on the partnerships and practices that emerged as a result. I will also consider moments of crisis and tension, which proved to be of special importance for understanding of the process.

It goes without saying that the story of Senster confirms what we already know about the formative power of media art (see Nichlos 1988; Graham 2002; Paul 2007; Graham \& Gfader 2008; Graham \& Cook 2010). During the Senster project a hybrid community of artists, scientists and craftsmen have formed. Distances between Turing- and Duchamplands have underpinned its framework. It is evident that claims that conservation and curatorship of new media art demands skills that surpass academic or museum education still have value. As is the need for developing the knowledge and skills amongst professionals working in the field. The materiality of a piece determines the kind of work to a great extent. The need to use source codes, signal detectors and DIY peripheral electronics place those kind of projects beyond the realms of the museum laboratory into the maze of schrotts, automobile repair shops, online flea markets. Creating closer partnerships with external techcompanies, who until lately have remained on the margins of the art world, is one of the consequences. The so far closed-off networks working within elitist cultural institutions need to open up to a wider collaboration.

Telling the Senster's story from the perspective of skills crises and restriction can add to this. It focuses our awareness on the manner in which the "experts" representing different professions tend to act. And it highlights how modes of behaviour conform to what is considered as culturally sanctioned in either the art or tech world. Consequently, some intrinsic connections between disciplines are exposed. This analysis allows us to move from a discussion on bridging the gaps between the tech and art worlds to the discussion on making use of commonalities in the context of media art curatorship.

\section{SENSTER 2.0}

What is called Senster 2.0 here is a project that aims to reactivate a 5-meter long steel skeleton of a cybernetic sculpture created by Edward Ihnatowicz in 1968.

The installation was constructed to interact with the public, communicating with a set of microphones, Doppler sensors and a machine code operating with hydraulic actuators that moved the sculpture. P9201 prototype computer was used to process the data.

At the end of the 1960s, Ichnatowicz, a Polish-born London- based artist, while presenting his Sound 
Activated Mobile (SAM) at the Cybernetic Serendipity, was invited by James Gardner on behalf of the Philips health technology company to create a large-scale piece.

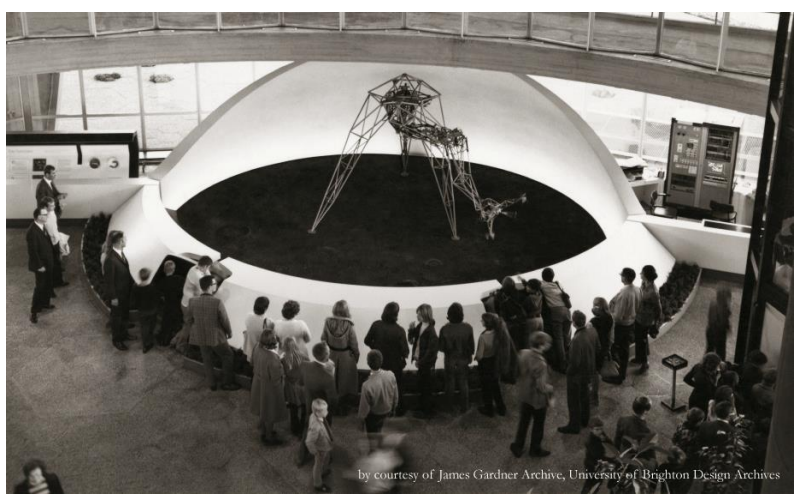

Figure 1: Edward Ihnatowicz, the Senster, Evoluon (Eindhoven) c. 1970; photo: James Gardner Archive, by courtesy of University of Brighton Design Archives.

Innatowicz' work was transported to the Netherlands and installed at Evoluon, Eindhoven the Philip's newly opened science-technology exhibition hall.

Thus the Senster became the third media artwork supported by the Dutch company, after Nicolas Schöffer kinetic art sculpture "CYSP 1" (1956) and Le Corbusier, Iannis Xenakis and Edgard Varèse's "Poème électronique" pavilion and environment (1958).

In the years following Eindhoven presentation the piece shared the fate of the majority of fragile media artworks. Despite its significance it remained inactive since the mid-1970s and was put on the list of lost media art pioneering projects in the first years of the $21^{\text {st }}$ century.

Detailed studies on the work were carried out by Alexandar Zivanovic (Zivanovic, Boyd Davis 2011) and Joanna Walewska (2015). Zivanovic has published online a significant amount of archival documentation connected with Ihnatowicz's cybernetic art (Zivanovic s.t.). Some documentation work has also been done at the Tate Modern.

In April 2017 AGH University of Science and Technology in Krakow purchased the installation from its previous owners. At present it is housed at the Faculty of Humanities where work on its renovation is progress.

\section{TIMELINE, WORKFLOW AND PROFESSIONS}

A detailed history of the project is being published as "The Senster Diaries" online blog (Olszewska 2018). For the purpose of this paper a graph illustrating overall contribution by different professions is appended (Figure 1). It has been compiled based on the data from the project's files. A contribution of each profession is laid out according to the amount of time invested by the project's participants. The work, which was outsourced, is also included.

The Senster 2.0 has been conceived as an interdisciplinary project and the integration of academic communities has from the outset been one of its aims. The intention was to create partnerships between members of the newly established Faculty of Humanities and the fellows and students at the AGH University of Science and Technology in Krakow.

The project work is carried out in a laboratory environment. The core team consists of nine members although currently the full list of those involved at different stages exceeds twenty. The main institutional support comes from the AGH University of Science and Technology in Krakow. Representatives of the fine Arts Academy have become partners.

The project emerged as a bottom-up, non-deadline university endeavour, Senster 2.0 has had quite a long prelude. The idea of working with the piece came up initially in 2009 but until 2016 its progress was intermittent. It began to gather momentum in 2016/2017 when, following successful sale negotiations, the sculpture found its way to Krakow. In this phase the project gained substantial funds, was granted the official support of the university, inter-university agreements were made and media promotion followed. As a consequence deadline obligations were imposed together with a need for structured and effective engagement.

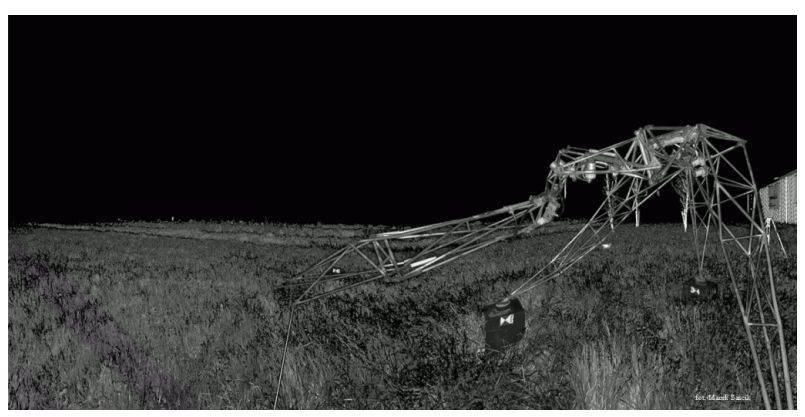

Figure 2: The Senster, Colijnsplaat, 2016; screenshot of 3d scan, by Marek Bascik \& co. 


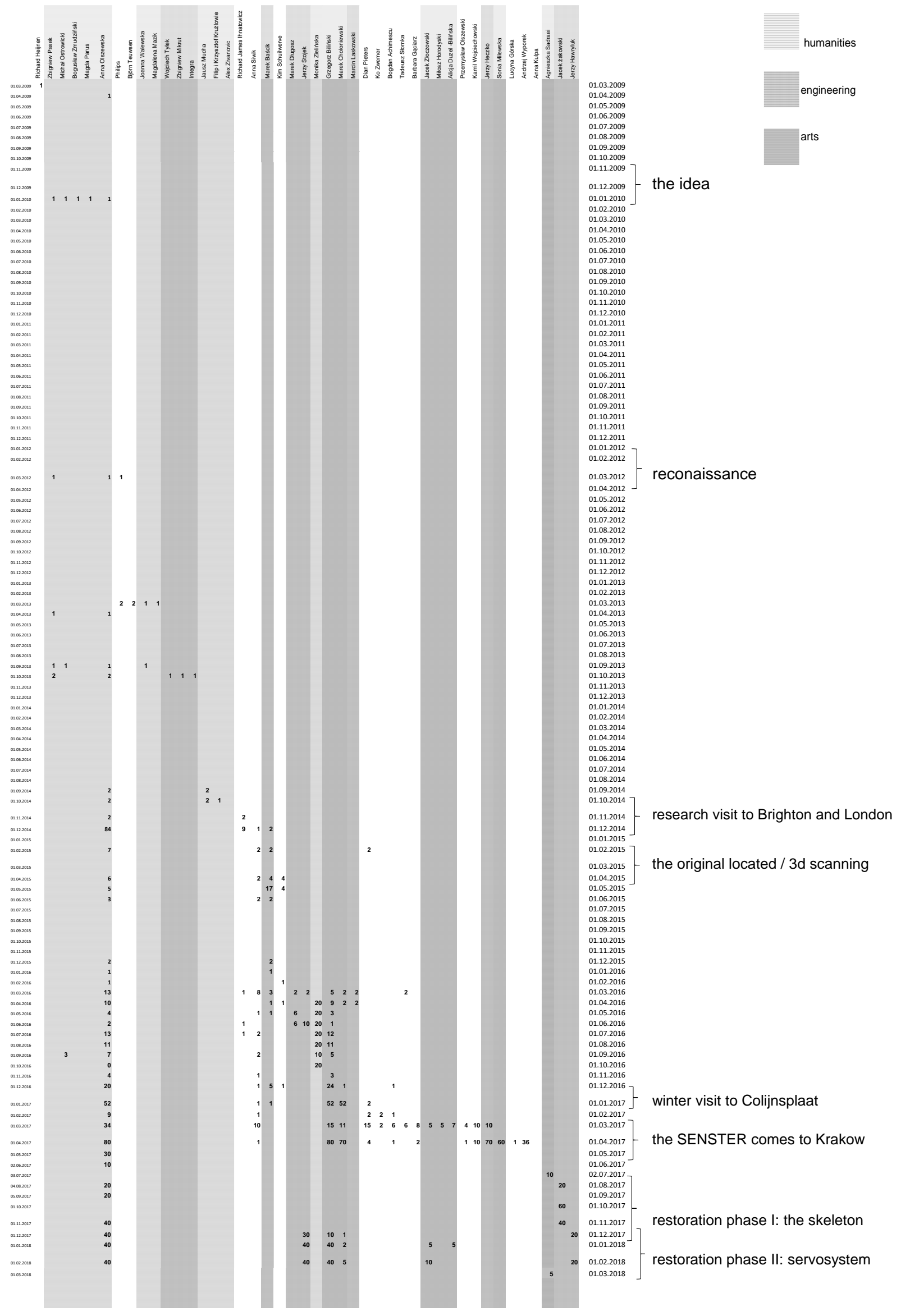

Figure 3: The SENSTER 2.0: workflow until March 2018, $y=$ timeline $x=$ contributions in hrs. approx. 
The graph presented in Figure 3 illustrates the dynamics of the project throughout its duration so far. The contribution of humanities is noticeably relatively as the largest; because the project has been conceived by representatives of the cultural studies faculty, they have become responsible for its sustenance. The contribution of the engineering team begins with the invitation of the engineers from the university community (the 3D scanning work was later outsourced). Their participation has increased since the start of the principal restoration phase. It should be noted that nearly half of the contribution comes from outside the university. Missing parts of the skeleton were supplied by an old automobile workshop. Servovalves and hydraulic pistons have been recovered by two industry system laboratories. Collaboration with local companies who run well-equipped workshops turned out to be much more than just outsourcing. They possess practical experience with old-school engineering systems and materials, which is highly valuable for the restoration. Skills and specialisations of the engineers range from the mechatronics and hydrostatic systems, to computer science and geodesy. The project also involved a wide group of traditional craft specialties including ironwork, welding and construction of electric circuits. Gradually the project also attracted representatives of various artistic disciplines such as multimedia, interior design and experimental music. They have been instrumental in organising two visits to Colijnsplaat (in January and April 2017), which resulted in the purchase of the original sculpture. The core team was formed at that time. Representatives of arts are in charge of recording and documenting the restoration work.

\section{NEW MODES OF PARTICIPATION: TO RESEARCH, TO DESIGN, TO PERFORM}

Because the project team and a community or network of collaborators have emerged bottom-up, some activities undertaken by its members have crossed the standard and stifling boundaries laid out by institutional frameworks. In consequence, humanities have not dominated the project, artists have not become the major creative force in its development, engineers are not solely responsible for calculations and mathematics and craftsmen have a say in the debates on the restoration philosophy. Inter-disciplinary relations are flexible (again, just like in many other media art cases). Consequently, there is no traditional distribution of competences: arts do not have a monopoly on creativity, techs for real-life application or humanities for interpretation. Instead, knowledge, experience and skills brought in by the members have found their expression in more topic- and activity-centred modes of participation defined as 'to design', 'to perform', 'to research'.
There are at least two reasons for which the division between researcher, designer and performer are relevant while telling the story of this project even though its scope extended beyond standard and narrow patterns of technology, humanities and arts ventures.

This is partly due to the general nature of current professional training. Both artists and engineers spend a lot of time being taught how to operate in a 'design mode'. Technicians are paid and appreciated for making decisions, their ability to enter creative interactions and implement specific scenarios and procedures. It could be argued that this brings them close to stage performers. On the other hand, academics from the field of humanities, tortured by the rigour of footnotes, exploring their way through the maze of colliding ideas and fragmentary archives, are most likely to take on responsibility for research and find common language with craftsmen searching for vintage techniques and materials.

The second argument comes from the observation on how these competencies interact in crisis. Working in a non-professional environment requires transgression of traditional standards and modes of participation. Lack of a stiff framework allows things to be done in a different way and in a different order. However, participants still tend to resort to their implicit modus operandum. Here are two examples that illustrate a typical situation.

A presentation of the project at a seminar at the sound engineering faculty was followed by a discussion on technological advancement of pioneering media art. This showed that from the humanities point of view researching the history of a restored object is indispensable. Its value lies in re-establishing the original concepts. However, the reaction of the majority of engineers present at the discussion was akin to those of designers. They argued against such research strategy, which in their opinion would produce out-dated technological trivia, not worth mentioning.

Another typical moment of confrontation came after one of the official presentations when issues of display have been discussed and mock-ups of the arrangement shown. The plans were presented for the very first time, with no previous consultation with rest of the core team members. This caused some controversy amongst the artists. After the meeting the author of the project (an architect) was asked why he had not advised the team on new developments before announcing them to a wider public audience. The objection was expressed by the architect's best friend who is a performing musician and composer. The response included arguments typical to the design mode of operation such as: "but this is only an initial presentation this 
will be developed, I'm sure there would be many more meetings like this".

The story of Senster 2.0 intertwines the phases of quiet design planning, long-term research and fast performance-like actions of application and implementation. These modes cross and go beyond the institutional, established boundaries of the disciplines involved. But some traditional restrictions remained and seem to have caused a clash and present challenges. In the case described above the design mode of thinking appears to have been dominant. At the same time, although the vast majority of research had so far been done by representatives of humanities, its results would be incomplete and much poorer without the contributions of the craftsmen and engineers. Representatives of the arts marked their presence during the application and implementation phases together with the technically trained part of the group. Interpretive and archiving activities have been shared between the representatives of the arts and humanities.

At present, the balance between three modes of participation and operation is maintained, with some continuing dominance of the design mode. Since work on the piece is still in progress it is hard to tell whether the combination of skills and knowledge will be sufficient for a successful completion. We may also ask to what extent this configuration and power balance are specific to this very case. Or does it apply to media art projects in IT department contributed to the realization (design mode) of some parts of the project. Electric technicians were also involved providing advice. Interventions from the technical staff (implementation/application mode) were indispensable following the opening due to the systems instability. Commenting on this project and comparing it with exhibitions of non-media artworks, the curator described it as engaging and risky. It required constant attention (execution mode) after the opening. She mentioned glitches, system collapses, daily problems with plugging in of the pieces and unexpected responses from the public.

Overall, it appears that the historic modes of working are being reframed. Implementation/application or execution skills (fast decision-making, response and interaction) are required during the whole period of the exposition. The exhibit design activity is a responsibility of the technical departments rather than graphic designers. So we may expect that if in the future media art enters the mainstream of museum practice a new kind of a professional may join the core exhibition/project. general, and does it tell us anything about mechanisms of contemporary culture. The last question is beyond the scope of the current paper. However, observations in relation to the Senster 2.0 project remain relevant in relation to comparable museum projects.

I would also like to consider applying this perspective to the analysis of a media art exhibition. I will specifically refer to the exhibition called 'Nonsense Technologies', presented by the MOCAK Museum of Contemporary Art in Krakow. Both Senster 2.0 and the MOCAK events have taken place simultaneously, and in the same city, but they engaged different participants and applied different frameworks. The MOCAK exhibition included works by two contemporary artists Przemysław Jasielski and Reiner Prohaska. Background research was carried out and curatorial narrative provided by Martyna Sobczyk and Przemysław Jasielski. The conceptual context was presented in the exhibition catalogue (Nonsense Technologies 2018). Interactive instruments, large-scale apparatus and installations comprising furniture-scale plastic objects were installed in the exhibition halls. The whole was installed during a three-week period, average for this kind of exhibition. Since the works were shown for the first time there were some complicated logistic issues. The artists brought in their own installers but support from the museum's technical crew was of importance. Members of the

However, this shift is not apparent to the same degree in cases of media pieces created by an individual artist. I have asked Przemysław Jasielski about the creation of Leviathan (2013), one of his pieces presented at the MOCAK 2018 exhibition. It has a form of a large-scale autonomic instrument comprising a giant tube vibrating with low sound, whenever movement is sensed by its electronic system. It turns out that the artist's system of work is classic. Although he outsourced the construction of the skeleton, all the conceptual and conception work, construction of electronic modules and tuning of the final sculpture was his own. In this case through long-term, individual engagement the artist has decided to improve his skills by learning how to design electronics modules.

\section{USING THE GAPS: CONCLUSION}

The case study presented here provides no evidence that media art projects through creation of multidisciplinary networks bridge the gaps between disciplines in a straightforward manner.

From the story of Senster we learn mostly about short-term, ad hoc interactions between 
participants from differing and perhaps traditionally inconsistent intellectual backgrounds.

Observations on design, execution and research show that it is likely that new practices will evolve along with educational systems that program the participants to instinctively adopt those modes of operation they have learnt during their professional training. These practices have the greatest chance to evolve in those situations where there is a need and enthusiasm for developing commonality through entering into new modes of participation and operation.

It appears that increasingly in collaborative, multidisciplinary projects participants are willing to explore new fields but during the moment of crisis or when fast action is needed, they instinctively resort to the methodologies and modes of operation they are familiar with or have been trained to follow. In other words, it remains standard practice that if a professional trained in the humanities dabbles in engineering it is more likely they would explore concepts and history rather than switching to design mode and construct a system. For the same reason it is so hard to persuade an IT engineer to carry out archival research to find a historic machine code. They would probably be more inclined to engage in the design rather than the research mode.

It is possible that the reason for this is that during a project such as Senster 2.0 contacts within networks seem to be more ad hoc and not sufficiently deep and long-lasting to guarantee a systematic dissemination, sharing and absorption of new knowledge, competencies and skills. This is not an environment conducive to in-depth learning of new skills, such as programming in $\mathrm{C \#}$ or becoming an expert in contemporary art.

So perhaps a modernist idea of scientificexperimental-open-museum-art-laboratory is but a utopia, and will not lead to the emergence of new practices. Perhaps so-called reframed media art curating will have no impact that would reach beyond the museums' walls.

On the other hand, the history of technological innovations abounds in projects where an art institution was used as a testing ground or used for the public output for emerging technological solutions. The story of young Siemens programmer Georg Nees sending his works to Max Bense can be a particularly representative example to this.
Or maybe we will use the gaps in connection, sharing and absorption to rethink our modes of operating and participating, and begin appreciating and developing environments for artists and engineers to be able to merge design with in depth research or humanists to engage in execution, implementation and real-life fast action mode.

\section{REFERENCES}

Graham B. (2002) An Interview with Benjamin Weil. In CRUMB Interviews.

http://www.crumbweb.org/getInterviewDetail.php?id $=13 \& \mathrm{op}=3$ (retrieved 17 March 2018).

Graham, B. and Cook, S. (2010) Rethinking Curating: Art after New Media-Leonardo Books. The MIT Press.

Graham B. and Gfader V., (2008) Interview with Laura Fernández \& Marcos García. In CRUMB Interviews.

http://www.crumbweb.org/getInterviewDetail.php?id $=32 \&$ ts $=1520878679 \&$ op $=3 \&$ sublink $=11$ (retrieved 17 March 2018).

Nichols, B. (1988) The Work of Culture in the Age of Cybernetic Systems. Screen, 29(1):22-46.

Olszewska A. (2018) The Senster: Diaries. http://senster.agh.edu.pl/dzienniki// (retrieved 17 March 2018).

Paul Ch. (2007) The Myth of ImmaterialityPresenting and Preserving New Media. In Grau O. (ed.). MediaArtHistories, MIT Press, Cambridge, MA.

Walewska J. (2015) Portret artysty jako inżyniera. Twórczość Edwarda Innatowicza / Portrait of the artist as an engineer: the works of Edward Innatowicz. Wydawnictwo Naukowe UMK, Toruń. (in Polish).

Zivanovic A. (s.t.) The Senster. http://www.senster.com/ihnatowicz/senster/ (retrieved 17 March 2018).

Zivanovic, A. and Boyd Davis, S. (2011) Elegant motion: The Senster and other cybernetic sculptures by Edward Ihnatowicz. Kybernetes, 40(1/2):47-62. 